\title{
From Preparedness to Coordination: Operational Excellence in Post-disaster Supply \\ Chain Management in Africa
}

\begin{abstract}
Preparation and coordination have come to dominate discourse on operational excellence in post disaster supply chain management. In this paper we explore the critical success factors (CSF) of operations excellence in post-disaster operations management in Africa, using indepth interviews with disaster management practitioners. Available studies have often focused on the commercial supply chains, but rarely on the critical success factors in service excellence in post disaster management operations in Africa. Using in-depth semi-structured interviews and desk-top data collection techniques from disaster management experts in Ghana a number of factors were identified. Employing thematic data analysis technique, these factors were categorised into eight (8) themes: management and administration, resources, political, governance structure, socio-cultural, education and training, infrastructure, and stakeholder involvement and co-operation.
\end{abstract}

Keywords: Humanitarian operations, Supply Chain Management, Africa, Ghana, Politics 


\subsection{Introduction}

The past decade has witnessed several scholarly interests exploring the nature and form of the operational excellence in post-disaster operations management specifically in Africa. Operational excellence, these scholars argue, needs to be better defined in post disaster supply management (source?). Supply chain management has received extant literature devoted to various parts of the subject (Gibson et al. 2005). These include, but are not limited to: the use of technology (Balcik et al. 2010), the role of information technology (IT) (Crumbly and Carter 2015), innovation in supply chains (Balcik et al. 2010), phases of supply chain (Ludema and Roos 2000; Altay and Green 2006), fleet management (Martinez et al. 2011), planning and controlling of supply chains (Cooper et al. 1997), communication (Wang et al. 2017), risk management in supply chain (Cigolini and Rossi 2006; Gualandris and Kalchschmidt 2017; Wang et al. 2017), coordination (Thomas and Kopczak 2005; Wassenhove et al. 2006), and collaboration (Wagner and Thakur-Weigold 2018), among others. From the era of its inception in the early 1980s, supply chain management has over the years often been used to describe the planning and controlling of the materials, information, cash flows, and the logistics activities within a company and between companies (Cooper et al. 1997). Thus, supply chain consists of all the parties involved, directly or indirectly, in satisfying a customer's need (Chopra and Meindl 2007). One of the areas being discussed in recent years by academics within the supply chain management literature is supply chain management operations within the humanitarian logistics (Sahebi et al. 2017). Humanitarian operations management is maturing as a discipline in recent years (Heaslip 2018), however, until the past decade scant attention had been paid to this research area - 
this is despite the numerous and increasing number of disasters around the world arising from advancements in technology and human activities.

The term "disaster" is usually reserved for "a serious disruption of the functioning of society, causing widespread human, material or environmental losses which exceed the ability of the affected people to cope using only its own resources” (United Nations, 1992, 21). This humanitarian logistics has to do with supply chain management that addresses disasters such as earthquakes, terrorist attacks, tsunamis, hurricanes, epidemics, droughts, famines, and wars are situations (Sahebi et al. 2017). The examples offered above indicate that these disasters that call for humanitarian logistics could either be man-made or caused by nature (China, 2001; Wassenhove 2006; Sahebi et al. 2017; Shareef et al. 2018; Zhang et al. 2019). A natural disaster is a possibly damaging natural occurrence or there is the possibility that such an occurrence will happen within a given period and area (China, 2001). In most cases nevertheless, complex emergencies involve both man-made (e.g., armed conflict, wars) and natural disasters (e.g., famine) (Sahebi et al. 2017). However, little is known about the critical success factors in operational excellence in supply chain management during post disaster operations. Identifying these critical success factors is very important for disaster management practitioners in order to contextualise and design the most effective plan for post- disaster management activities. Identifying these critical success factors will also provide policy-makers with evidence for informed decision-making regarding the applicability of different disaster management interventions in Africa.

Prior studies have focused mainly on the commercial supply chains (Pettit and Beresford 2009). Therefore, the need to explore that critical success factors within the humanitarian operations cannot be overemphasised. Further, in this study, we focus on all forms of disasters in post-disaster operations excellence. The closest study to this current research is the work of Pettit and Beresford (2009) and Zhou, Huang and Zhang (2011). Pettit 
and Beresford (2009) for instance, used a literature review of commercial supply chain studies to conceptualise the critical success factors that could be applied in humanitarian supply chain management. Similarly, Zhou, Huang and Zhang (2011) used fuzzy logic and decision-making trial and evaluation laboratory (DEMATEL) to identify critical success factors in emergency management. Although these offer a conceptualised picture of the critical success factors of humanitarian operations, they do not offer empirical evidence as this study seeks to do. By soliciting the views of disaster management operators, we offer empirical evidence to this effect.

We focused on an African context for the following reasons. First, many strategies have been adopted by the African region to deal with disaster management strategies (The AU/NEPAD 2004; Kalambay and Abdulmumini 2018). However, despite all these strategic policies and programmes, the region remains comparatively the only continent with a continuous rise in disasters (The AU/NEPAD 2004; Kalambay and Abdulmumini 2018). This study, therefore, explores the factors that will increase the likelihood of being able to manage disaster effectively and efficiently by focusing on the post-disaster critical success factors. Further, the negative effects of disaster are more severe in developing countries than their developed countries’ counterparts (Loayza et al. 2012) and therefore, the need to explore the critical success factors that will enhance our understanding of how these disasters could be managed effectively and efficiently is long overdue. Findings will offer guidance on how policy makers and practitioners may devise better and informed strategies to deal with disaster management operations. Findings can also serve as a foundation for future research in disaster operations in the African continent and other developing countries with similar local dynamics.

We focus on the Ghanaian context for two reasons. One, like many African countries there has been a continuous rise in disasters over the years despite the various strategic 
policies and programmes devised by the region to reduce the risk of disasters (AsumaduSarkodie et al. 2015). The devastating effects of disaster in Ghana is enormous, it leads to loss of life and livelihoods, in turn hampering socio-economic development (Aboagye et al. 2013; Asumadu-Sarkodie et al. 2015; NADMO, 2018). Further, Ghana continues to face similar disasters every year - they include: flooding, fire outbreaks, cholera, storms and landslides (Aboagye et al. 2013; Asumadu-Sarkodie et al. 2015; The National Disaster Management Organisation (NADMO) 2018). In fact, over the years, flooding and outbreak of fire have become a norm and an annual occurrence rather than an exception in the country (Aboagye et al. 2013; Asumadu-Sarkodie et al. 2015).

Two, Ghana happens to be one of the countries that have not been able to implement all the strategies and policies devised to deal with disaster management in the region (The AU/NEPAD 2004; Kalambay and Abdulmumini 2018). This indicates that most of the management strategies being used to manage disasters may be on an ad-hoc basis thus having an impact on success within their operations. Therefore, there is the need to explore how they are able to be successful in dealing with post-disaster humanitarian supply chain management operations despite this non-implementation.

This study offers several contributions to both theory and practice. One; this study addresses the growing call for studies into the critical success factors in humanitarian operations in an African context. Even though CSFs have been widely studied in the context of supply chain management, they have mainly done so in the context of commercial supply chains -research but have paid little attention to CSFs in the context of humanitarian supply chain. The very few that have focused on humanitarian operations have done so conceptually (Pettit and Beresford 2009; Zhou et al. 2011) and therefore, this study offers empirical evidence to the existing literature. In contrast to existing literature, our approach solicits the views of multiple stakeholders directly involved in the operations of disaster management. 
This is necessary to deepen our understanding of stakeholders' perspectives about the critical success factors in service excellence in post-disaster supply chain management operations. This study will set a direction for operations management researchers in order to pay attention to this research area using empirical studies. Further, studying the critical success factors within the humanitarian operations management, we deepen our understanding of the factors that need to be focussed on if humanitarian operations are to be successful within an African context and other developing countries with similar dynamics. Practically, practitioners and policy makers will be able to use the findings as a guide in post-disasters management operations. This will help them to make informed decisions about how to best handle supply chain management operations in order to be successful.

The remainder of the study is presented as follows: Section 2 presents the literature review by focussing on disaster management in Africa and developing countries; and critical success factors of supply chain management within disaster management. Section 3 describes the research method and provides a description of the sample selection. It provides a deliberation of the research approach with specific emphasis on how the in-depth semistructured interviews were operationalised. Section 4 presents the results and analysis. Section 5 presents a discussion of the study focusing on the implications of the results to academics, practitioners and policy makers of humanitarian disaster management. The last section (6) concludes the study by summarising the key findings and drawing on the contributions. This section also presents the limitations of the study and makes recommendations for future studies.

\subsection{A Review of the Disaster Management System in Africa}

Like many other regions, Africa is faced with continuous challenges such as conflicts and natural emergencies leading to many injuries, death, population displacement, destruction of 
health facilities and disruption of services, hence, contributing to different forms and types of disasters in these countries (Kalambay and Abdulmumini, 2018). Similar to many developed and developing countries (Kalambay and Abdulmumini, 2018), African regions have devised many strategies in dealing with disaster management; both at the pre-disaster and postdisaster management stages. Whilst some strategies deal mainly with either pre-disaster or post-disaster management; others have focussed on both. Taking the latter strategies for instance, in 1997, at the 47th session of the Regional Committee, African countries adopted a five-year disaster management strategy titled the Resolution AFR/RC47/R1 on the Regional Strategy for Emergency and Humanitarian Action (Kalambay and Abdulmumini, 2018). Among other considerations, the main purpose of the five-year strategy was to call on all member states to strengthen their institutional capacity for emergency preparedness and response through self-reliance (Kalambay and Abdulmumini, 2018). Similarly, African countries adopted a strategy called Public Health Emergency Fund in 2009 after the $59^{\text {th }}$ session of the WHO Regional Committee for Africa. The main purpose of this strategy was to improve the funding of disaster preparedness and response (Kalambay and Abdulmumini 2018). However, despite the adoption of all these strategic management plans, not all the member countries have been able to implement them all. Hence, the challenges of pre- and post-disaster management continue to face the African region (Kalambay and Abdulmumini 2018), thus hampering their ability to deal with disaster problems when they do occur.

In relation to pre-disaster strategies, in 2004, a regional strategy to reduce disaster risk was developed to help in sustainability development. The African Union, in collaboration with the New Partnership for Africa's Development (NEPAD) and International Strategy for Disaster Reduction (ISDR) was tasked to develop a strategic approach to improving and enhancing their effectiveness and efficiency by emphasizing disaster risk reduction (The AU/NEPAD, 2004). In order to achieve the goal of reducing the risk of disaster, six main 
objectives were adopted. These included: (1) increased political commitment to disaster risk reduction; (2) improved identification and assessment of disaster risks; (3) enhancement of knowledge management for disaster risk reduction; (4) increased public awareness of disaster risk reduction; (5) improved governance of disaster risk reduction institutions; and (6) integration of disaster risk reduction in emergency response management. In the same fashion, in 2012, at the 62nd session of the Regional Committee for Africa, the region adopted a comprehensive 10-year regional strategy for the health disaster risk management (DRM) policy (Olu et al. 2016). This was adopted in response to the World Health Organization's core commitments to health DRM and the Hyogo Framework. Consequently, all the 47 member states were supposed to adopt this strategic plan.

Regarding post-disaster strategies, Reid and Niekerk (2008) developed a model using grounded theory methodology through the use of the internet and focus group interviews for the management of disaster within South Africa. In the model, Reid and Niekerk (2008) prescribe six main levels of responses to post-disaster management. They include: one, at the A level one response constitutes the response to an incident involving a single agency that has statutory responsibility to deal with the primary effects of the incident. The scope of management applied in a level one response is that of vertical command and decisionmaking, exercised by the Agency Commander using agency resources from an Agency Command Post (ACP). Reporting is executed in terms of internal agency operating protocols. Two, A level two response applies to an incident demanding the response of the primary agency, which has statutory responsibilities to deal with the primary effects of the incident; and support agencies from other disciplines within the same jurisdiction, which have statutory responsibility to deal with the secondary effects of the incident being responded to. Three, at level three response constitutes a response involving multiple agencies to an incident, the magnitude of which, demands resources in excess of the available own resource 
thresholds of any single agency which has statutory responsibility to deal with the primary or secondary effects of the incident. Four, A Level four response applies to a single occurrence of such magnitude that it demands human, equipment or organisational capabilities and/or decision making which exceeds local capacity. Fifth, A Level five response applies to an occurrence of such magnitude that it exceeds the statutory and jurisdictional capabilities of a single district or metropolitan municipality to deal with it effectively or a series of Level four response operations taking place simultaneously in the jurisdiction of a province. Finally, A Level six response applies to an occurrence of such magnitude that it exceeds the statutory and jurisdictional capabilities of a single province to deal with it effectively or a series of level five response operations taking place simultaneously in the country. Even though the empirical data that was used to develop the model was based within the South African context, its application could be applied to many countries with similar local dynamics.

\subsection{The Impact of Disaster in Developing Countries}

The impact of disaster in developing countries and Africa in particular are huge ranging from human to material impacts. Specifically, these impacts may lead to socio-economic effects (Alca'ntara-Ayala 2002; Oloruntoba and Gray 2006; Lin et al. 2011; Loayza et al. 2012; Strobl 2012; Sahebi et al. 2017; Kalambay and Abdulmumini 2018); and Ghana is no exception (Aboagye et al. 2013; Asumadu-Sarkodie et al. 2015; Bempah and Oyhus, 2017). In 2007 alone, the estimated loss of economic impact of disaster relating to deaths in Africa was to be US\$ 117.2 million; and in 2008, it was estimated that well over 12 million people were displaced refugees (Kalambay and Abdulmumini 2018). The impact of these disasters on growth and development cannot be overemphasised as studies and reports over the years show that disaster has devastating effects on economic growth of states worldwide (United Nations Development Programme 2004; Alca'ntara-Ayala 2002; Schumacher and Strobl 
2011; Loayza et al. 2012; Strobl 2012; Klomp and Valckx 2014). However, the degree of impact often depends on the type and nature of disaster, the magnitude of the disaster, and the different types of economic, social, political and cultural vulnerabilities that exist in the country where the disaster occurs (Alca'ntara-Ayala 2002; Loayza et al. 2012; Strobl 2012).

However, despite the negative effects that are often associated with disaster occurrences, some studies have reported a mixed effect, both negative and positive (AlbalaBertrand 1993; Tol and Leek 1999; Loayza et al. 2012). For instance, in the study of natural disasters and growth, Loayza et al. (2012) found that disasters do affect economic growth but not always negatively and that some disasters may lead to economic growth to some sectors within the country where that particular disaster occurs. Citing examples, Loayza et al. (2012) found that positive effects are often reported in moderate disasters such as flooding, nevertheless, the effects becomes negative if the flooding is severe. It can be deduced from the literature that the impact of disaster in developing countries is huge and therefore, the need to investigate the critical success factors in operational management of these disasters when they occur, cannot be overemphasised.

\subsection{Disaster and Supply Chain Management Operations}

Despite the technological advancement in human endeavour, evidence suggests that disasters are on the increase (Sahebi et al. 2017). Therefore, it is vital to manage disaster in order to minimize their impact. A number of approaches and/or strategies used in the operational management of these disasters have been proposed by academics and practitioners alike. These include but not limited to: coordination, communication, transportation, food, accommodation, among others. For instance, in the work of Lin et al. (2011) a logistics model is proposed for managing emergency supply of critical items in the aftermath of a disaster. They categorised this into two - the Genetic Algorithm (GA)-based approach; and 
the decomposition and assignment heuristic (DAH). Regarding coordination practices, challenges and opportunities in humanitarian relief chains, Balcik et al. (2010) suggested the need to adopt and/or adapt sophisticated and innovative supply chain management coordination practices within the commercial supply chain management. Even though numerous supply chain management practices have been suggested by prior studies, it can be said that the type and form of management approach(es) used in dealing with a disaster is phased-dependent; thus, the stage of the disaster will determine the type of approaches that needs to be used.

Wagner and Thakur-Weigold (2018) discussed collaboration in humanitarian supply chains, and analysed the causes of their dysfunctional operations in relation to the use of humanitarian resources. They observed that a number of factors account of dysfunctions in collaborations in humanitarian operations; which lead to information disorder among humanitarian actors. The factors that affect collaborations that lead to information distortions include: unusually high time pressure under which fieldworker work, an extremely dynamic and uncertain environment, inadequate infrastructure, different performance metrics, and very diverse educational levels and biographies of the staff assigned to manage and operate within the field. However, they observed that these challenges are more associated with the immediate aftermath of post-disaster supply chain operations rather than at the recovery and ongoing humanitarian aid operations.

\subsection{Phases of Disaster Management Operations}

Humanitarian operations management literature indicates that there are several disaster phases. For instance, Ludema and Roos (2000) grouped disaster phases into three emergency relief, rehabilitation, and development phases. Similarly, Safran (2003) put them into: prevention, transition, and recovery. Pettit and Beresford (2005) also categorised them: 
preparedness, response, and recovery. Altay and Green (2006) added a fourth - mitigation, preparedness, response, and recovery. However, Altay et al. (2018) added one more phase reconstruction, however, they assert that the recovery and re-construction phases are related in somewhat and they are associated with activities that involve the restoration of all aspects of the disaster's effect on the community and the return of the local economy to some degree of normality.

Despite the different categorisations made by various authors, it can be deduced that these phases can mainly be categorised into two pre-disaster and post-disaster management phases. In this study, the focus is on the post-disaster management phase(s). This current study investigates the critical success factors in post-disaster supply chain management by focusing on multiple operational areas.

\subsection{Challenges facing Disaster Operational Management}

Humanitarian supply chains consist of more than just humanitarian organizations (Sahebi et al. (2017); and it consists of other players such as donor agencies, non-governmental organisations (NGOs), governments, the military, logistics service providers, and suppliers (Jahre, et al. 2007). Others such as Oloruntoba and Gray (2006) further add aid recipients as being major players in the humanitarian supply chain and made a further distinction between international and national, including community-based organizations as players. 'Humanitarian relief environments engage a large number and variety of actors, each with different missions, interests, capacity, and logistics expertise’ (Balcik et al. 2010, 22); and they are faced with a number of challenges in their humanitarian reliefs chains in their operations (Balcik et al. 2010; Martinez et al. 2011). These challenges range from human to materials, internal to external, technical to non-technical. Consequently, this has attracted the attention of many researchers who have devoted their studies to identifying these challenges. 
The work of Balcik et al. (2010) on coordination in humanitarian relief chains identified a number of challenges facing coordination in the operations of humanitarian relief chains. These included: procurement coordination which is affected by procedure, funding, limited information technology and cost. Warehousing coordination mechanisms such as temporary warehouses due to the sudden nature of disasters, the cost involved in keeping permanent warehouses for unforeseeable future and unsolicited in-kind donations of relief supplies from donors. Transportation coordination mechanisms which come from the difficulties presented by lumpy, uncertain demand and extremely variable global shipping destinations - thus, no coordination in shipper collaborations in relief chains. Similarly, Thomas and Kopczak (2005), Wassenhove et al. (2006) and Balcik et al. (2010) assert that coordination is a major issue in humanitarian supply chain management due to the numerous actors associated with disaster relief chains.

Martinez et al. (2011) also identified a number of factors that are critical to the operations of disaster management chains, affecting the smooth operations of relief chains. However, they focused mainly on transportation in the form of vehicle fleet management within the chain of disaster management operations. Among others, they identified: environmental, bad roads, procurement process, funding, uncertainty and demands, tax status, exchange rate and security issues. Similarly, Sahebi et al. (2017) used panel discussions to identify twenty-two (22) barriers and challenges facing humanitarian supply chain management within Iran using a case study of Tehran's Red Crescent Societies. The twentyeight barriers and challenges were categorised into nine (9) and are: managerial, human resources, political, financial, education, informational, tools and resources, environmental and culture. Whereas some of the challenges are barriers occurring at a specific phase (predisaster and post-disaster) of the supply chain management, others occur in both phases. However, the most important barriers and challenges are: cultural, managerial and 
educational factors. The least important barriers include factors that relate to: environmental, informational and political respectively. In an assessment of strengthening health disaster risk management in Africa, Olu et al. (2016) identified several challenges that African countries faced in their implementation strategies. These included: inadequate political will and commitment resulting in poor funding for health disaster risk management, weak health systems, and a dearth of scientific evidence on mainstreaming disaster risk management and disaster risk reduction in longer-term health system development programmes.

\subsection{A Review of Key Success Factors in Disaster Management}

The existing literature indicates that there are a number of factors that are critical to the success of supply chain management in disaster management operations. However, these factors depend on the area of supply chain under investigation. These areas include but are not limited to: transportation (Pettit and Beresford 2009; Martinez et al. 2011), accommodation, food, medication, materials and equipment (Fritz Institute 2017; John et al. 2018), coordination (Thomas and Kopczak 2005; Wassenhove et al. 2006; Balcik et al. 2010), collaborations (Wagner and Thakur-Weigold 2018), stockpiling of relief items (Gonçalves and Castañeda 2018), infrastructure (Martinez et al. 2011), education and training of relief workers (Wagner and Thakur-Weigold 2018), fairness in relief items distributions (Anaya-Arenas et al. 2018), among others.

Taking transportation for instance, there are several factors that are critical to an effective and efficient operation of supply chain management during and after disaster management. For example, the study of vehicle fleet management in Africa, the Middle East and Europe by Martinez et al. (2011) used interviews in headquarters, regional and national levels within the International Committee of the Red Cross, the International Federation of Red Cross and Red Crescent Societies, the World Food Program and World Vision 
International. They revealed a number of factors that are critical to the success of disaster management in African countries - Kenya, Uganda and Mozambique. They include: one, external factors such as operating conditions and external demand uncertainty which affect both the coordination of field vehicle fleet management functions and program performance. Security issues which mandates fleets to be in convoys, lack of infrastructure and facilities which affects maintenance scheduling and fuel sourcing complex, especially in remote areas, driving conditions such as bad road network which affect vehicle life cycle, tax status and exchange rates which also affect vehicle procurement and disposal decisions. Environmental concerns such as pollution from international organisations and agencies are critical to the success of vehicle fleet management and high levels of beneficiary migration that brings about changes in the intensity of conflicts or the proximity of natural disasters to their homes generates demand uncertainty which translates into uncertainty of programme of transportation needs. Two, artificial transportation demand uncertainties such as lack of coordination in vehicle scheduling and routing which is influenced by the high dynamism and/or unstable conditions in developing countries within which these programmes are carried. Lack of coordination between programmes due to uncertainty also means that vehicles being dispatched for these humanitarian disaster activities are not fixed and keep changing all the time. This lack of coordination which creates artificial uncertainty and demand comes from the national level. This agrees with earlier studies conducted by Balcik et al. (2010), which identified coordination as a fundamental challenge facing humanitarian relief chains. Three, funding of vehicles for disaster operations is also critical as the study found that vehicle procurement and purchases are made by donors and as such there are times when national operations have to wait until funding is available before they purchase or replace them. 
One critical success within the area of disaster management operations is information sharing among the various agencies that help manage disasters. For instance, using an experimental research strategy in the study of information diffusion among humanitarian agencies in a cluster, Altay and Pal (2014) found that when cluster leads act as information hubs, information reaches its target faster, enabling a prompt humanitarian response to victims. Thus, the willingness of agencies within clusters of humanitarian organisation to share information leads to faster response by the various agencies, more especially at the later stages of humanitarian response operations. The implication is that information sharing among humanitarian organisations within a cluster is critical and crucial to the success of their operations. However, the speed of the response that is based on the information is quality and trust dependent. Thus, for information sharing among agencies within clusters to be effective, the quality of the information being shared is equally important and there must be trust among the agencies (Altay and Pal 2014). Similarly, Kabra and Ramesh (2016) that the use of IT is an important factor that enhances the performance of the humanitarian relief supply chain, however, this is dependent on other critical factors such as mutual trust, agility, flexibility, and adaptability within the humanitarian organisations.

In relation to critical success factors within the humanitarian operations, the literature is scanty and with regards to an African context, literature is scarce. The very few have focused mainly on conceptual studies. For example, the work of Pettit and Beresford (2009) used a literature review of commercial supply chain studies to conceptualise the critical success factors that could be applied in humanitarian supply chain management. They identified several factors that are critical to humanitarian operations excellence. One, strategic planning; addressing how long-term decision making is required and will therefore need to be dealt with at the highest level of an organisation. Two, inventory management; with the emphasis that if supply chain is to be successful then there should be adequate storage of inventory at 
local places before they are properly distributed to where they are needed for humanitarian activities. Three, transport and capacity planning; how transportation of fleets are planned, since disaster areas do not often have good transport networks when compared to the commercial supply chains which are distributed in normal transport routes. Four, information management and technology utilisation; how information is managed during operations and the effective use of technology to help to control disaster operations. Five, human resource management; how the ability of an aid organisation to respond effectively will be significantly impacted upon by how it has organised its human resources. Six, continuous improvement and collaboration - how supply chain solutions are to meet the needs of the market place. The humanitarian organisations need to focus on having a holistic and continuous improvement approach to meeting the needs of the victims. This provides a conceptual overview of the critical success factors of humanitarian operations and therefore, empirical evidence from humanitarian operations workers is important.

Similarly, Zhou, Huang and Zhang (2011) used fuzzy logic and decision-making trial and evaluation laboratory (DEMATEL) to identify critical success factors in emergency management. They identified twenty factors that impact on emergency management humanitarian operations systems, including: well-planned emergency relief supply systems; reasonable organizational structure and clear awareness of responsibilities; applicable emergency response plans and regulations; financial measures and prior planning of logistic centres and shelters; education campaign on disaster prevention and response; specific training of professionals such as rescue workers and medical staff; strong ability to send out specific early warnings about potential hazards; regular organization of simulated disaster exercise; very short response time to start the emergency plan; government unity of leadership to plan and coordinate as a whole; the involvement and support of army; timely and accurate relief needs assessment; the security of relief aids during distribution and 
transportation; clear procedure of reporting and submitting information; effective emergency information system to ensure information transferring; application of modern logistics technology; reconstruction and staff comforting; statistics and feedback of loss information; evaluation on the efficiency and effectiveness of the management system; continuous improvement of the operational system of emergency management. However, only five of these factors are critical to the success of the humanitarian operations and they are: reasonable organizational structure and clear awareness of responsibilities, effective emergency information system to ensure information transferring, government unity of leadership to plan and coordinate as a whole, application of modern logistics technology and finally, continuous improvement of the operational system of emergency management. Whilst these findings offer a methodology and framework for the identification of critical success factors, they do not provide empirical evidence from field workers perspectives within humanitarian operations organisations and therefore, this calls for further and practical evidence.

\subsection{Data Collection and Methodology}

A systematic literature review was initially conducted in order to identify the critical success factors of supply chain management in post-disaster humanitarian operations (Tranfield et al., 2003). We followed the processes prescribed by Khan et al. (2003), Ke et al. (2009) and Lu et al. (2014). In this procedure, the first step is Framing Questions for a Review (Khan et al., 2003) and therefore the literature review started by framing the main research question. Search keywords are required in order to meet the requirements of research (Ke et al., 2009). Lu et al. (2014) advised that in order to ensure search range of the review, there is the need to used plural forms of search keywords. The second step focuses on the sources of data selection - this must be a comprehensive and extensive search from relevant databases and 
journals (Khan et al., 2003). Therefore, in order to obtain a lot of relevant citations, journals in the appropriate field of study need to be identified and selected for the literature review (Lu et al., 2014). Accordingly, we used ScienceDirect as the main and first search engine, where most of the journals in the field of supply chain management in post-disaster humanitarian operations are published. Having reviewed all the supply chain management; operations management and research; humanitarian operations and production management; and project management journals, we realised that other journals existed but were not listed in all the journals that are listed in ScienceDirect. Hence, we used the ABS Journal Rankings to select other journals that publish supply chain and operations management papers. Following this, we used Google Scholar - we assumed that there could be other relevant literature from Ph.D. theses; non-ranked journals and industry practitioners' reports. The third step was to perform a preliminary search using the search keywords within the defined specific domains of Titles, Keywords, and Abstract (Lu et al., 2014). These search keywords are inserted and entered into the identified and selected journal databases (Ke et al., 2009; Lu et al., 2014). In order to do that, we first conducted a general search on supply chain management in post-disaster humanitarian operations critical success factors. Words and phrases such as: supply chain management in post-disaster humanitarian operations; success factors in supply chain management; humanitarian operations management; humanitarian operations management in developing countries; effects of disaster in developing countries; effects of disaster in developing Africa; why post-disaster operations are successful and challenges facing disaster operations, were used. This was done to identify the general knowledge about supply chain management in post-disaster humanitarian operations and factors that are critical to supply chain management in post-disaster humanitarian operations in general and African region supply chain management in post-disaster humanitarian operations. The search needs to be rigorous, without any language restrictions, and this 
should be subject to the flow from the research question(s) as a priority (Khan et al., 2003). Lu et al. (2014) and Ke et al. (2009) argue that in this step, the search should be confined to a parameter search so that consistency could be assured. In step 4 involves the Assessing the Quality of Studies to ensure academic rigor (Khan et al., 2003). At this stage, the search words and phrases are then narrowed down to critical success factors in supply chain management in post-disaster humanitarian operations, which is more specific to the research topic. The step five (5) is then followed by summarising the data through detailed review by analysing and synthesising of the relevant literature identified (Lu et al., 2014). At this stage, the literature could be tabulated and put into themes. In agreement with Khan et al., (2003) and Lu et al. (2014), this was tabulated based on similarities in the findings. Lastly, step six focuses on Interpreting the Findings - at this stage, the data is synthesized and interpreted from the tabulation and then recommendations made using the evidence of strengths and weaknesses (Khan et al. 2003). In this research, we did not perform that final stage as the study is not an exclusively systematic literature paper; and hence, we grouped the findings in order to identify the research gaps. On the basis of the findings, we realised that little is researched about the subject in the study's context and therefore, there was a need to employ an exploratory study using semi-structured interviews, which is enshrined in the qualitative research strategy and interpretivist research philosophy (Bryman 2012; Saunders et al. 2015; Bryman and Bell 2015).

We follow the interpretivist research philosophy in this research — which is a strategy that interprets the social roles of others in relation to a set of meanings (Saunders et al. 2015; and Bryman and Bell 2015). This philosophy evades unyielding structural frameworks and adopts a more flexible research structure which is rigorous enough to capture human interaction (Carson et al. 2001; and Black 2006). It favours the idea that the investigator and his informants are co-dependant and mutually interactive (Hudson and Ozanne 1988). In this 
qualitative form of research, the investigator is more interested in getting a saturated form of information from a respondent — hence, it emphasises on words rather than quantification (Denzin et al. 2005; and Bryman et al, 2015). Its studies participants' meanings and the relationships between them while using a variety of data collection techniques such as focus groups, observations and interviews (Saunders et al. 2015).

Another vital reason why qualitative data was considered for this study was that it allows participants to be heard, enabling the researcher to understand and interpret their opinions on the critical success factors on post-disaster management issues, which would lead to insightful findings. Additionally, the participants being interviewed consist mainly of disaster and humanitarian management experts with very busy work schedules. Therefore, it felt unsuitable to carry out quantitative research as it would have been time consuming and results would be more inaccurate compared to qualitative research.

Due to the interpretivist nature of this study, we found it appropriate to use interviews for the data collection. We considered a semi-structured interview since it allowed us to vary the sequence of questions and ask further probing questions depending on the participants' responses. It also gave us the opportunity to prioritise the important subjects whilst allowing the participant to give relevant open-ended answers. The intriguing answers that were obtained from respondents gave us a richer insight regarding the topic in question (Collis et al. 2014). We followed a checklist of questions to conduct the interview. This made it more feasible for us to compare and identify re-occurring themes (Saunders et al. 2015). All the interviews were on face-to-face basis, and this allowed us to observe the body language of the participant.

Using the purposive sampling approach, we sampled 20 key informants (13 senior management staff and 7 Field workers) from the National Disaster Management Organisation in Ghana (NADMO) (See full profile of respondents presented in Table 3 in the appendix); to 
yield insight from their illuminative and rich information sources (Patton, 2002). The numbers of participants were not pre-determined at the beginning of the interviews, but data was collected until we reached a saturation point - where the data had been thoroughly optimised such that no new information emerged from participants (Morse, 1995, 2000; Hill et al., 2005; Silverman, 2013; Guest et al., 2006). We focused mainly on NADMO as it is the main disaster management agency in Ghana. Its core responsibilities are: 1. manage disaster prevention and/or mitigation issues in Ghana; 2. coordinate activities before and during emergencies; and 3. Coordinate and manage post disaster rehabilitation, resettlement, and reconstruction issues. We created a cordial interview environment prior to the commencement of each interview. All interviews were undertaken within the participant's working environment by pre-booking an appointment; which ensured they felt comfortable and hence gave more reliable answers. During the interviews, the snowball technique was also used to identify further participants (Bryman, 2012; Saunders et al., 2012).

In terms of the structuring of the interview, the most important questions were asked first - this gave us the opportunity to elaborate on any fascinating answers the interviewee gave. Due to ethical and privacy concerns, we also gained permission from the interviewee to record them. We then asked questions associated with the literature review and referred to the objectives constantly. Each interview lasted approximately 30 to 45 minutes. Data collection occurred between April 1, 2018 and June 30, 2018. The fact that the research approach was slightly more inductive than deductive meant that we thematically analysed our data. Braun and Clark (2006) described as a method for identifying, analysing, and reporting patterns within qualitative data.

A 6-stage framework is proposed by Braun and Clark (2012) on how to use thematic analysis. For the first stage we familiarised ourselves with the data collected before coding and looking for patterns. The second stage involved the identification of initial codes for the 
data collected. The first and second stages are imperative because the third stage involved looking for themes from the coded data. We highlighted the key words and phrases mentioned by the respondents and henceforth explored any interesting themes accordingly. We then reviewed the themes to ensure that the data formed a coherent pattern. A thematic map was used to help us envisage the relationship between the themes. The penultimate stage was to capture the essence of what each theme was indicating and deciding whether any theme fitted into the overall narrative which includes the post disaster success factors in developing countries.

Each interview was transcribed on the following day after the interview. The transcribed data was uploaded into the NVivo11 and reduced by selecting, focusing and condensing the information. This was done so that the researchers could know when saturated point is reached (Morse, 1995, 2000; Hill et al., 2005; Silverman, 2013; Guest et al., 2006). The data was analysed using thematic analysis through a line by line approach to identify themes. After the line by line coding, content and cross-case analysis was conducted to code sentences which explained the themes. Axial coding was also conducted to identify and explain the relationship between the various themes and sub-themes of critical success factors of post-disaster supply chain operations in Ghana. The themes developed from the open coding were grouped together - on the basis of their relationship with each other. This was then first mapped against the themes and then expanded into overarching and sub-themes to explain the relationship between the main themes and sub-themes (Braun and Clarke 2006). This was then reviewed further to ensure that they work in relation to the data set through visiting and comparing the data several times to verify and confirm the themes identified (Miles and Huberman 1994). Themes that did not relate to the research question or were already touched upon in the literature review were overlooked. As advised by Braun and Clarke (2012), which states that, the results should be then reported; we reported the results 


\subsection{Analysis and Discussions}

\subsection{The Disaster Geography and Management in Ghana}

Ghana's development and demographic dynamics puts the country at risk of disasters. These changes are often related to rural poverty, rapid urbanization, rural-urban migration, and environmental degradation (NADMO, 2015). Thus, the disaster risk zones are spread all over the country. For example, Table 1 below shows that fire disaster is often prevalent in Greater Accra, Ashanti, Eastern and Western regions of Ghana. There is also wider spread risk of crop pest and diseases across the 10 regions of Ghana.

Table 1: Geographical Distribution of Geological Disasters.

\begin{tabular}{|l|l|}
\hline Disasters Types & Vulnerable Areas \\
\hline Earthquakes & Greater Accra, Central, Eastern, Western and Volta Regions \\
\hline Flood & Greater Accra, Northern, Upper East and Upper West regions \\
\hline Fire & Greater Accra, Ashanti, Eastern and Western regions \\
\hline Soil erosion & $\begin{array}{l}\text { Eastern (Akwapim Ridge), Ashanti (Mampong Scarp) and } \\
\text { Northern Regions (Gambaga Scarp) Volta (Kabakaba Hills) }\end{array}$ \\
\hline $\begin{array}{l}\text { Crop pest and disease } \\
\text { infestation }\end{array}$ & $\begin{array}{l}\text { Widespread (mostly in Ashanti, Brong Ahafo, Central, Eastern, } \\
\text { Volta and Western Regions) }\end{array}$ \\
\hline Expansive soils & Widespread across the 10 regions \\
\hline Coastal erosion & $\begin{array}{l}\text { Greater Accra, Ashanti, Central, Northern, Volta and Western } \\
\text { Regions }\end{array}$ \\
\hline Ground subsidence & $\begin{array}{l}\text { Coasts of Ghana: Volta (Dzita), Greater Accra (Ada), Central } \\
\text { (Cape Coast - Elmina) and Western (Shama) Regions }\end{array}$ \\
\hline
\end{tabular}

Source: Author's compilation from various NADMO reports

We observed that the widespread nature of Ghana's disaster zones has compelled authorities to conduct a holistic hazard mapping of the country. This mapping activity has been well 
formulated with support from institutions that may be involved at the management stage (see

Table 2). For instance, hazard mapping for fire was mapped by the Ghana Fire Service with support from NADMO. The hiatus we identified during our interviews is that not all the institutions are resourced enough to manage post-disaster management issues in the country.

Table 2 below further confirms the lack of capacity in disaster management issues. For instance, most of the institutions seek consultancy services to make inputs into their disaster management issues, which can be very expensive.

Table 2: $\quad$ Hazard Mapping Activities, Inputs and Responsible Agencies

\begin{tabular}{|c|c|c|c|c|}
\hline \begin{tabular}{|l} 
Disaster \\
Type \\
\end{tabular} & Activity & Inputs & Lead Agency(ies) & Collaborating Agencies \\
\hline $\begin{array}{l}\text { Pest \& Insect } \\
\text { Infestation }\end{array}$ & $\begin{array}{l}\text { National survey on pest and insect } \\
\text { outbreaks }\end{array}$ & $\begin{array}{l}\text { Consultancy } \\
\text { Services }\end{array}$ & $\begin{array}{l}\text { Ministry of Food and } \\
\text { Agriculture (MOFA) }\end{array}$ & $\begin{array}{l}\text { Food and Drugs board, COCOBOD, Centre for } \\
\text { scientific and industrial research, Universities, } \\
\text { NADMO }\end{array}$ \\
\hline \begin{tabular}{|l|} 
Disease \\
(Epidemics)
\end{tabular} & $\begin{array}{l}\text { Mapping of geographical areas of } \\
\text { high disease incidence }\end{array}$ & $\begin{array}{l}\text { Consultancy } \\
\text { Services }\end{array}$ & Ghana Health Service & $\begin{array}{l}\text { NGOs, World Health Organisation, Universities } \\
\text { (College of Health Sciences), NADMO }\end{array}$ \\
\hline \multirow{4}{*}{ Fires } & $\begin{array}{l}\text { Preparation of maps showing the } \\
\text { location of food, cash crops and } \\
\text { silos. }\end{array}$ & \begin{tabular}{|l|} 
Base Maps, \\
Consultancy \\
Services
\end{tabular} & $\begin{array}{l}\text { Survey Dept, Forestry } \\
\text { Commission, MOFA }\end{array}$ & $\begin{array}{l}\text { Universities, Ghana National Fire Service, NADMO, } \\
\text { Environmental Protection Agency }\end{array}$ \\
\hline & $\begin{array}{l}\text { Mapping of high, medium and low } \\
\text { bushfire prone areas }\end{array}$ & $\begin{array}{l}\text { Geographic } \\
\text { Information } \\
\text { System (GIS) }\end{array}$ & $\begin{array}{l}\text { Ghana National Fire Service, } \\
\text { Forestry Commission }\end{array}$ & $\begin{array}{l}\text { Ministry of Water Resources, Works and Housing, } \\
\text { Dept. of Game \& Wildlife }\end{array}$ \\
\hline & $\begin{array}{l}\text { Preparation of thematic maps on } \\
\text { fire hazards }\end{array}$ & $\begin{array}{l}\text { Base Maps, } \\
\text { Consultancy Services }\end{array}$ & Survey Dept. & $\begin{array}{l}\text { Universities, Ghana National Fire Service, } \\
\text { NADMO, Environmental Protection Agency }\end{array}$ \\
\hline & \multicolumn{2}{|c|}{$\begin{array}{l}\text { Preparation of maps showing the } \\
\text { location of forest reserves in the } \\
\text { country. }\end{array}$} & $\begin{array}{l}\text { Forestry Commission, Survey } \\
\text { Dept. }\end{array}$ & $\begin{array}{l}\text { Environmental Protection Agency, Ministries } \\
\text { (EPA), Departments and Agencies, Ghana National } \\
\text { Fire Service, NADMO }\end{array}$ \\
\hline \multirow[b]{5}{*}{$\begin{array}{l}\text { Hydrometeor } \\
\text { ological }\end{array}$} & Mapping of flood prone areas & \begin{tabular}{|l|} 
Base maps, \\
Consultancy Services \\
\end{tabular} & Ghana Meteorological Service & $\begin{array}{l}\text { Water Research Institute, Dept. of Urban Roads, } \\
\text { Forestry Dept, EPA, NADMO }\end{array}$ \\
\hline & $\begin{array}{l}\text { Reading and recording of } \\
\text { rainfall \& water levels }\end{array}$ & \begin{tabular}{|l} 
Rain gauges \& \\
automatic water level \\
recorders
\end{tabular} & $\begin{array}{l}\text { Ghana Meteorological Service, } \\
\text { Hydrological Dept, Water } \\
\text { Research Institute }\end{array}$ & Ghana Highways Authority, NADMO \\
\hline & $\begin{array}{l}\text { Preparation of drainage master } \\
\text { Plans }\end{array}$ & Consultancy Services & $\begin{array}{l}\text { Hydrological Services } \\
\text { Department }\end{array}$ & Hydrological Services Department, NADMO \\
\hline & Preparation of Flood Insurance & Consultancy Services & \begin{tabular}{|l|l} 
National Insurance \\
Commission
\end{tabular} & State Insurance Commission \\
\hline & $\begin{array}{l}\text { Risk Maps (FIRM) } \\
\text { Installation of early warning } \\
\text { systems }\end{array}$ & Consultancy Services & \begin{tabular}{|l|}
$\begin{array}{l}\text { Ghana Meteorological Service, } \\
\text { Hydrological } \\
\text { Services Department }\end{array}$ \\
\end{tabular} & Universities and the Survey Department \\
\hline & $\begin{array}{l}\text { Preparation of geological hazard } \\
\text { maps }\end{array}$ & $\begin{array}{l}\text { Base maps, } \\
\text { Consultancy Services }\end{array}$ & $\begin{array}{l}\text { Geological Survey, } \\
\text { Department, /NADMO }\end{array}$ & \multirow{2}{*}{$\begin{array}{l}\text { Survey Dept., Council for Scientific and Industrial } \\
\text { Research, Ministry of Lands \& Forestry, } \\
\text { Universities, Mines Dept., Environmental Protection } \\
\text { Agency. }\end{array}$} \\
\hline Geological & Monitoring of geological hazards & $\begin{array}{l}\text { Seismographs , } \\
\text { Consultancy Services }\end{array}$ & $\begin{array}{l}\text { Geological Survey Department, } \\
\text { /NADMO }\end{array}$ & \\
\hline
\end{tabular}




\subsection{Semi-Structured Interview Results}

A number of factors were identified as critical success factors of operations excellence in post-disaster supply chain management in Ghana. Using thematic analysis techniques, the factors are categorised as: management and administration, resources, political, governance structure, socio-cultural, education and training, infrastructure and stakeholder involvement and co-operation.

\subsubsection{Management and Administration Practices}

Several critical success factors were identified under management and administration practices that may lead to operational excellence in post-disaster operations. These included: communication, coordination, timely response to disasters, data collection and record keeping of victims and customer service practices. However, these factors are related in a way. For example, for effective coordination to be possible there is the need to have effective communication among the various actors or stakeholders of relief workers. Further, there must be collection of data from victims before it can be kept; there is the need to communication with victims as well as other stakeholders.

Regarding communication; respondents were of the view that for post-disaster operations to be effective, efficient and excellent, then one of the fundamental factors is effective communication among the various players of the operations. A senior disaster support officer at NADMO stated:

\footnotetext{
"I think the key success factor is effective and excellent communication among the key stakeholders. In this country, sometimes it's difficult to speak to those in higher authorities ... you have to go through a lot of bureaucratic and protocol to speak to those in authorities. So, if there is specific communication plan, and everybody [stakeholders] knows whom to speak to and they know that they have the duty and accountability to the victims or the ordinary citizens, then, disaster operations will be easy and successful [R1].”
}

Even though the focus of the study was on post-disaster operations, the respondents went further, adding that effective communication does not only happen at the post-disaster management phase but should begin from pre-disaster phase. Thus, there should be pre-planned communication channels so that when disaster strikes, every player knows where, when and how to make the appropriate communications. The operations coordinator at NADMO indicated that: 
“... but effective and efficient communication does not happen in a vacuum, there must be well planned communication channels even before the communication takes place after a disaster, .... you cannot use ad-hoc communication measures and be successful. [R18].”

This finding confirms that existing literature indicates that effective communication is panacea to project success in order to avoid duplication of information, and to provide stakeholders with information (Cooper et al. 2004; Close, 2006; Weijermars 2009; Wong et al. 2009; Wi and Jung 2010). Similarly, Ochieg and Price (2010) identified that internal and external communication is the invisible glue that holds dislocated multicultural project teams together. However, afore mentioned studies were not conducted in humanitarian operations and therefore, this finding adds to the literature the importance of communication in operations management. In humanitarian operations management Altay and Pal (2014) found information diffusion amongst various players of operational management is a key success factor and this can only be achieved through effective communication. The implication is that without effective communication, post-disaster operations are bound to fail, hence, the need to use the appropriate form and channel of communication to communicate among the various stakeholders involved in these operations.

Most of the respondents (R1-R10, R15, R17) said that coordination is a factor that can affect postdisaster operations. They argued that if there is effective coordination among the various operational agencies, then success will be likely. For instance, a senior officer (R1) said that for them to be successful there must be effective coordination between the headquarters, which is based in the capital city of Ghana, and their offices in the regions and the districts. Also, there are other players such as the Red Cross Society and other NGOs and private corporations who help in post-disaster operations and therefore, “NADMO must coordinate all of them, so that there will not be duplications and chaos in the distribution of relief items". R17, who is an officer at NADMO, said that:

\footnotetext{
"this is one of the most difficult part, especially if the disaster is very huge and damaging ... in these circumstances, people become emotional and want to help, so they don't want to follow instructions from us. Sometimes too, they want to score or attract public attention that they are also helping or doing philanthropist job, so they move in without consulting us or listening to appropriate instructions. So, I think that if we are able to coordinate all of these players well, then we can definitely attain success”
}

The implication is that coordination of the various activities is key for successful operations in disaster operations, as previous studies in humanitarian relief have identified coordination as a major challenge to 
excellent operations (Thomas and Kopczak 2005; Wassenhove et al. 2006; Balcik et al. 2010). This means that in order for operational success in disaster management, practitioners and policy makers must garner the necessary coordination skills that can help them coordinate the numerous actors and/or players involved.

Some respondents said that timely response to disaster can also help in achieving success (R2, R7, R10, R18). "If you want to be successful in these situations, I think you need to respond quickly and timely’ (R7). They argue that even though, in most cases, it is the security and fire service personnel who are first on the scene of disasters a timely response to their call can also help save lives and reduce the emotional stress on victims. In the words of R18:

"You know in most of these disasters, it is the fire service and other security agencies that are called on first, but we mus also act as soon as we are needed, especially issues that have to deal with emotions and stress. Sometimes, when they see us [NADMO workers], psychologically, they feel a little bit relief because they know we are going to help them with relie items.”

Timely response to issues and even in meetings is a major problem in Ghana and many African countries and therefore, this finding draws attention to the fact that responding to issues, including disaster operations on time, is a critical component of successful operations in disaster management.

Another key factor they mentioned is accurate data collection and recording keeping of victims. All the respondents said that, when disaster strikes, they go to the affected areas and assess the situation, collect victim's data including the degree of damage, the type and level of help that individuals may need before distributing relief items or sending them to the appropriate quarters such as hospitals for further treatment if necessary. They said that this must be kept for future support. For example, R2 said that:

"We register them first because if you don't register you can't know the number of people who are affected before you report to the authorities. Once you have the register, you will know the number of people who are affected. So, you relocate them to a safer area. If it is minor, you register them and know the number of people who are affected. With this you know the number of people you are referring to. The father, the number of wives and children and then you will know how to distribute it. You will know the number of people in one room. So, we take all these into considerations before giving the items out.”

Another factor that they mentioned is customer service. Respondents are of the view that, even though what victims are looking for in such a situation is being safe and survival, as far as NADMO workers are concerned, respecting the dignity of victims is also part of their success criterion and is therefore considered as success factor if their victims are taken good care of during their operations. 
"During the management and operations of post-disaster, victims do not really care too much about how they receive the service and Ghana in particular people don't care too much about customer service - more especially when the victims think we are doing them a favour, but I don't think this should be the case, otherwise we will not be successful in the ' 'eyes' of the international community ... I have lived abroad before, and I know how customer service is important, so I try to incorporate this into our operations. (R4).”

Even though many developing countries do not really care about customer's services when compared to their advanced countries counterparts, by offering disaster victims good customer services during operations will help them to be successful. This also implies that people in Ghana are now beginning to recognise the need to offer victims customer service.

Overall, it can be said that even though other factors may influence operational excellence in postdisaster management, without excellent management and administration practices within the operational organisations and/or institutions, success will be hard to achieve, hence, the need to take these practices seriously. Other studies such as Sahebi et al. (2017) also identified managerial challenges in operations management and therefore, operational management practitioners cannot take these practices for granted if they are supposed to be successful.

\subsubsection{Resources Factors}

All the respondents mentioned resources as the fundamental critical success factor for excellent operations in post-disaster management operations in Ghana, even though, some referred to resources in different forms and types. These included both tangible and intangible resources. Among them are: relief items such as, means of transport; finances; machines and equipment; roofing sheets; blankets; first aid kits; bandages; medicines; non-perishable foods; tents; among others. However, the most recurring theme and what respondents laid much emphasis on, was financial resources.

In relation to financial resources, respondents are of the view that financial resources are the bane of the rest of the resources and other operational success factors - in that if there was adequate funding, then it can support other operations. For instance, one senior officer said that:

"the major problem we have as an organisation is resources ... and when I say resources, I am referring to financial resources or funding; sources of funding. We are more or less government agency or organisation, funded by the 
government but sometimes we don't have enough funds in our coffers ... here were are talking about disasters and you don't know when it will happen and when it happens, you don't know that magnitude of it, so it difficult to know the exact budget, so the best way is to have more than enough money in your coffers, but this is not the case. I don't blame the government, but I think they can do more; and also the corporate world should do more to help us financially, so that we can be successful. (R4).”

Even though they said financial resources are fundamental, they also mentioned, availability of first aid and relief items as well as machines and equipment. Seven of the respondents (R1, R4, R8-R11, R17) opined that if there are enough first aid and relief items in depots and warehouses, then they can be successful. R3 for example said that; to be successful in post-disaster operations, we will need first aid items and relief items such as "roofing sheets, blankets, first aid kits, bandage, medicines, non-perishable foods, tents, etc’’

They also mentioned means of transport as a success factor. They are of the view that to be successful, the means of transport should always be available. However, they said that in most cases, especially in rural areas, they lack these resources and therefore they often struggle to reach out to the victims as quickly as expected.

Resources, especially financial resources, are one of the fundamental problems facing many African countries in their operations. Even though in advanced countries such as the UK, USA and Germany, humanitarian organisations rely on donations in their operations, as the central government contributes significantly to their operations. However, in most African countries, instead of relying on the local donations and the government agencies, they rely on foreign donors instead and this affects their operations. Impliedly, their success is hinged on external funding - hence, being critical to their operational success. Here, resource dependency theory (RDT) is evidenced - RDT states that organisations rely on resources external to them and therefore power resides in the ability to own resources (Pfeffer and Salackcik 1978; Hillman et al. 2009). Other studies in operations management have identified resources as a major factor that impact on success. However, some of them such as Sahebi et al. (2017) linked resources to only the human aspect. This means that operational excellence of humanitarian operations is dependent on these resources and in this case, external donors in particular. 


\subsubsection{Political Factors}

The findings revealed that a number of political related factors are critical to the success of operational excellence of supply chain management within humanitarian operations in post-disaster management. These included central government support of the national organisation that is in charge of managing disasters This is in the form of financial and logistical support; and the central government's willingness to help the affected areas using their political affiliation as their basis for support or otherwise.

Regarding the former, the respondents opined that central government full support plays a key role in being successful or not. They argue that this is so because NADMO is a state agency, funded mainly by the tax payer's money - with funding being allocated during budget, therefore the level of funding depends on the government's desire to support the course of the organisation. It was revealed that in theory, all governments fully support the organisation but in practice, sometimes they do not get the full backing of the government, especially if the disaster is not big and does not have public attention. R8 for example said that:

\footnotetext{
"in theory, every government fully support the institution but in practice, the degree of support differs from government to government. ... my brother, you know in Ghana and most African countries, government always want to score politica points in everything, every situation, so what happens is that when the problem is big and has the attention of the media and the general public, they [politicians] would want to put in the maximum best, but otherwise, forget it [not support]. So, I will say that political support without being picky will help as succeed in these operations.”
}

Regarding the latter, surprisingly, two field workers (R5\&R9) mentioned that “political will”' to help affected areas and victims are crucial to their success. They are of the view that two reasons account for this - one, when the majority of the affected area or victims are perceived to belong to a particular political party that will determine the government's desire to help. They said that often, the central governments are more sympathetic to their party members; however, this also depends on the magnitude of the disaster. Whilst small disasters face this problem, serious and national disasters do not face much of this problem and "therefore, to be successful, the operations of the organisation should receive equal support from the government in post-disaster operations" (R9). Two, if the disaster is man-made which is caused by government agency or operations, the government is less supportive of victims. In the words of R: 
"if the disaster is caused by government agencies, let say Roads and Highways Authorities pull down people's houses and structures that have been built illegally or are blocking the waterways, even though the central government may not be fully aware, they [central government] are reluctant to help the displaced persons. In these operations, sometimes people die, and they need NADMO to go and help them. The government are sometimes unwilling to help, because it will be like conflict of interest but we as an organisation, it doesn't matter the nature and type of disaster, [and] we must help. So do not rule away the political will of the government out when it comes to critical success factors.”

Partisanship politics has been researched extensively; however, they are discussed in relation to political accountability of public officials rather than humanitarian operations excellence (Bob-Milliar 2012; Asunka 2015; Luna 2015). This therefore adds a different dimension to the growing research in politics by identifying partisanship politics. Other studies in Africa have also identified political will as a major challenge in humanitarian operations (Olu et al. 2016); however, their findings did not find partisanship politics as a challenge. This finding, therefore, introduces a new concept, partisanship politics, into the political discourses as a factor impacting on humanitarian operations successes and excellence.

\subsubsection{Governance Structure Factors}

Closely related to political factors is the governance structure of the NADMO. These included the appointment of the central and top leadership by the central government and as such are more or less indirectly controlled by the central government and the president of the country; and therefore, the central government controls the decisions and activities of the organisation. This means that, even though in theory, the organisation is autonomous, in practice, they are not and therefore, their recruitment processes, planning and activities are structured to suit the central government. Therefore, their success is susceptible to the whips and caprices of the president and central government.

This view was shared by all the senior officers and two field officers (R1-R4, R5\&R9); and they said that one of the key factors that can make them successful is "being fully autonomous". They mentioned that even though NADMO is autonomous, this is only in "books and theory" (R2; R9) and that practically; the organisation is run by the central government. R4 said:

\footnotetext{
"How can you say NADMO is autonomous when all the top-level leaders at national and regional levels are political appointments? Even those at the districts are political appointment except that they [such appointments] are categorically stated. My friend, even getting a job here [NADMO], is most often by 'whom you know'; pure politics. So to me, if we [NADMO operations] want to achieve success or operational excellence as you put it, then the organisation should be free
} 
from politics and political appointment, because if not the structure will be controlled by the government, hence may not be successful."

This finding is controversial, especially given that the central government provides the main funds to NADMO. Thus, one would expect that if the government is the main financier, they will be involved in the structure and their operations. In essence, the electorates will expect to attribute success or failure to the government; hence, they will be tempted to be part of their structure and operations. However, this could be detached from the government control - which will imply that appointment of leadership to the organisation should be apolitical, hence, improving on their autonomy.

Respondents also stated that, one of the factors that are critical to their success is the decision-making channels within the institution. They argue that in most cases, decisions are made from the headquarters and passed on down to the region and to the districts level; and that it should be other way round in the postdisaster operations. They said that, often, senior management makes decisions on what to do without first visiting the scene of the disaster; and that if they want to be successful, then they should allow the field workers to go to the grounds to assess the situation before making recommendations to the senior staff (R8, R13, R16\& R18). R8 said:

"I think the current situation where there is top-down approach to decision-making sometimes does not help in our operations. It will be better that in all cases, those on the field makes the assessments and send their recommendations before the top management makes the decisions ... but I don't really think this may work, given that these disasters are sudden and needs quick responses; maybe in the long term support but right aftermath of disaster, it may not work.”

Even though the bottom-up approach in the decision-making channel is what will provide the platform for successful operations of post-disaster, this may not be totally workable, especially in a country where a lot of the fieldworkers are recruited on partisanship basis rather than on merits. The implication is that some of them might not be people who are qualified-hence, may not possess the technical know-how to make good judgements, hence, making good decisions. They may also be swayed by their political affiliation, as studies in the country suggest that political affiliation makes people fail to hold their political official accountable for their stewardship (Bob-Miliar 2012; Asunka 2015). In the same way, they may make decisions that could favour their political parties to the detriment of the victims. 


\subsubsection{Socio-Cultural Factors}

One of the most surprising finding is the socio-cultural behaviour of relief workers and the mind-set of victims that are based on belief systems enshrined in cultural orientation. It was revealed that some field workers attitude towards work (which is regarded as government work) is poor. Also, some victims attribute certain disasters to spirituality and therefore, their mind-set about addressing the disaster becomes difficult in some situations; and this affects post-disaster supply chain operations management. Whilst the former could be linked to colonial rule; the latter could be linked to how religious Ghanaians are.

Respondents said that, sometimes when certain disasters occur, the victims and the local community of the victims believe that the occurrence of the disaster in question might have been caused by the " gods of the land' and that nobody can help them unless they appease the gods through sacrifices and pouring of libations. In this case, relief workers will not be able to work effectively until the sacrifices and prayers have been offered to the gods. The respondents were of the view that if their operations are to be successful, then people's cultural orientation about this belief system must be changed through education. Other authors have also observed that societal perception about disasters impacts on how the contribute in risk reduction (Liu et al. 2018). However, this was specific to flooding. This adds a new dimension to the success factors of humanitarian operations, as previous studies have not discussed how belief system affects humanitarian operations excellence. The implications are that mass education is needed if there is supposed to be operational excellence in post-disaster management. This finding is consistent with World Factbook (2018) which states that Ghanaians are very religious and place value and importance to cultural and/or belief systems. Thus, Ghanaians place more importance to belief systems in their schemes of activities (Amponsah, 2010; Damoah, 2015; Damoah et al., 2015; World Factbook, 2018). Further, the global religious index places Ghana as number one in the ranking - with $96 \%$ of Ghanaians classified as religious (WIN-Gallup International, 2012) and adhere to religious values in their activities. On the other hand, respondents also said that the mind-set and attitude of some field workers are fundamental success factors. They are of the view that some workers perceive that they are doing victims a favour by helping them after 
disaster instead of perceiving their operations as work and “ ... until such attitude and mind-set is changed, it will affect our success’' (R3). R1 added that:

"Some of our workers also think that this is government work, and so they can do whatever they want and will still be paid. This is bad working ethics but that comes back to how they are appointed or recruited -thus political appointment and recruitments.”

R2 said that:

"Our social orientation and attitude towards government work in Ghana is very bad; elsewhere like UK and USA or even Germany, it's not like that. As a country, we have problem with patriotism and unless this is changed, it will be difficult to success as an organisation. This is not a problem peculiar to NADMO but all government institutions and organisations.”

Other studies such as Amponsah (2010), Damoah (2015) and Damoah et al. (2018) have identified Ghanaian attitude to public sector work to be poor; however, they were discussed in relation to project management. This means that Ghanaians need to be sensitised about the need to improve on their work attitude irrespective of the job being public work or charity or humanitarian operations.

\subsubsection{Education and Training}

The finding revealed that education and training are critical to operational excellence of humanitarian supply chain management in post-disaster management. Education and training came in two-folds - education of the general public and education and training of relief field workers.

With respect to the former, respondents were of the view that for post-disaster operations to be successful, the general public should be educated about common disasters that often occurs in Ghana and how to manage them. In this case, when it occurs, managing them through their operational team will be easy and successful. For instance, R14 said that:

"I do understand that you want success factors in post-disaster operations, but I can tell you that without proper and better pre-disaster education, then our [NADMO] operations will struggle to succeed. The general public must be educated, especially in areas which hold soo much believe about spiritual and belief systems of gods causing disasters. How can we be successful in our operations when this day and age, people think that flooding is caused by a curse or gods being angry with the people? My friend, it’s a problem and the only way is to sensitize people about this.”

On the other hand, others such as R1-R4, R15\&R17) said that to be successful, field workers need to have constant training and refresher courses to improve on how to management post-disasters. R1 argues that: 
"Most of our people do not have the required knowledge in managing certain situations and therefore training is very crucial in disaster management. Imaging you have a fieldworker who did political science in school and they are confronted with emotional issues to deal with on the field, obviously, he or she cannot do it, so there is the need to at least train the workers to have some level of basic knowledge about their areas of operations in order to be successful.”

Training and education of humanitarian operations workers has been identified as a key factor in humanitarian operations success (Wagner and Thakur-Weigold 2018). However, whilst the prior study is more specific on specific area of humanitarian operations, this current study looks at the bigger picture by looking at education and training in general - that looks at both the fieldworkers and the general public. The implication is that, disaster management organisations should not only focus their attention on staff education and training but also the prospective victims of disaster and/or the general public. By doing so, there will be some level of understanding between fieldworkers and victims of disaster during operations.

\subsubsection{Infrastructure}

The study revealed that for post-disaster operations to be successful and excellent, then infrastructures within the country are key factors. Among them are: healthcare facilities, road network, communication network, and depots and warehouses. Regarding healthcare facilities, they made particular reference to hospitals and clinics.

Most of the respondents (R1-R10, R15, R16\&R17) mentioned that Ghana is a developing country with a gap in healthcare infrastructural needs. The said that there are a lot of rural areas without proper clinics and hospitals, and others are without these healthcare facilities at all. They further stated that even those in the cities including the capital city (Accra) do not have enough capacity to accommodate regular healthcare seekers and therefore, struggle to accommodate disaster victims. They, therefore, argue that, if their work has to be successful, then these facilities are crucial, because in most cases they have to transfer victims of disaster to healthcare facilities after giving them first aid and others would need to be sent there straightaway. In the words of R17,

"One of the success factors, I must say is healthcare facilities - I mean good hospitals and clinics; some rural areas don' even have clinics, so if there is disaster, and after assessment and you want to transfer them to hospitals after first aid, how 
do you do that, where do you send them to? We work with them [healthcare providers] closely, so without them, we can' success. So, I can say with authority that, it a major success factor in our [NADMO] operations.”

Secondly, like many African countries (Martinez et al. 2011), respondents mentioned good road networks as a success factor by arguing that in order for the operations of post-disaster to be successful, then good road network across the country is essential.

"My brother, as a country, as I stated earlier, infrastructure deficit is serious, and it cut across all sectors and road network are even worse. Almost every district in the country has road network problem. So how do you want us to be successful if we are to transfer people from one district to the other or to the nearest healthcare centre? Until, this road network is sorted, forget about being successful in our dealings in terms of transportation. I am not talking about other transport network because they are not popular and some of them like air ambulance; we don't have them at all. So, what I am trying to say is that, modern good roads are necessary for us [NADMO] to succeed. (R17).”

Even though respondents mentioned that there has been an improvement in communication networks, significantly in terms of coverage and network operators, but the quality of the services rendered are poor and that affects their operations. In view of this, they said, for relief operations to work effectively and efficiently, and then a good communication network is needed.

Another infrastructure that is critical to the success of relief operations in post-disaster operations is depots and warehouses. All the respondents mentioned that there are inadequate warehouses and depots at the various regional and districts areas to store relief items and this affect their success and therefore, to be successful, availability of warehouses and depots in all regional and districts offices or areas are critical. R1 for instance said that:

"The institution needs warehouses and depots in all districts to succeed; this is because post-disaster operations do not start at post-disaster but rather at pre-disaster ... you need to equip yourself with relief items that are non-perishable, and these must be stored in a warehouse, so that you can easily fall on it when needed.”

R4 added that:

"when distributing relief items, you need to keep them a place before distributing them to the victims"' and therefore, ' .. to succeed, we [NADMO] need enough warehouses in all districts."

Similarly, Martinez et al. (2011) identified a number of factors that are critical to the operations of disaster management chains, which affects the smooth operations of relief chains. However, this study focused mainly on transportation in the form of vehicle fleet management within the chain of disaster management operations. These included: environmental, bad roads, procurement process, funding, uncertainty and demands, tax status and exchange rate, and security issues. Olu et al. (2016) also identified 
weak health systems in Africa as one of the fundamental challenges of disaster reduction in Africa. Implying that without infrastructural excellence, its will be extremely difficult for humanitarian operations to achieve success as this will hinder smooth running of the operations.

\subsubsection{Stakeholder's Involvement and Co-operation}

Stakeholder involvement and engagement was mentioned as a critical success factor for post-disaster operations in Ghana. Among those involved are the fire service, security agencies such as the police, military and immigration services, local community of victims, hospital workers, corporate entities and victims' corporations. They said that the organisation works in collaboration with these stakeholders and therefore their full cooperation is fundamental to their success. They argue that, even though in post-disaster operations, they work with these personnel and local community, more often than not their organisation [NADMO] is perceived to be the frontrunner and therefore any success or failure is often attributed to them. One of the most surprising arguments put forth by the majority of the fieldworkers is that, in some circumstances, the victims do not co-operate with them in the management processes and suggested that, there must be massive education about this. R11 for example said that; "as an organisation, we cannot succeed without the co-operation of other stakeholders involved, especially the victims themselves’. R10 stated that:

"The difficulty in these operations is that sometimes, the local community do not fully get involved; some even resist us because of their belief system about the disaster. Sometimes, they will pour libation and say all sorts of spiritual things before they allow us to work.”

This finding is in agreement with earlier studies such as Wagner and Thakur-Weigold (2018) which emphasised the need for effective collaboration among disaster relief workers in order to reduce information distortion. Even though the work of Wagner and Thakur-Weigold (2018) were specific on collaboration, this could be linked together since co-operations involved collaborations and/or could be used synonymously.

\subsection{Conclusions}


This study extends the humanitarian and supply chain management literature by exploring the critical success factors in post-disaster operations in Africa with Ghanaian evidence. Using semi-structured, face to face, in-depth interviews of 20 National Disaster Management Organisation (NADMO) senior officials and fieldworkers who are involved in managing post-disaster issues; a number of critical success factors were explored. Using a thematic data analysis approach, these factors were categorised into eight (8) main factors. These include: management and administration, resources, political, governance structure, socio-cultural, education and training, infrastructure, and stakeholder involvement and co-operation.

Regarding management and administration practices, the study revealed that effective communication and coordination among disaster management players is critical to its success. Other factors identified include timely response to the aftermath of disaster and accurate assessment data and safe keeping of victims and disaster records. Lastly, good customer service is a factor that needs to be followed in order to present the possibility of being successful in these operations. In relation to resources, many resources were identified as success factors. They include: financial, relief items, machines, medicines and equipment. However, financial resources are considered as the most important and fundamental to all - as finance is perceived to be the resource that can be used to access other resources.

Relative to political, the study revealed that political will and support to relief organisations is a critical success factors - because the central government is the one responsible for the allocation of budget for the operations of the institution. Even though other corporate entities make donations, they are mainly on an ad-hoc basis and therefore, cannot be relied upon for successful operations. Closely related to politics is the governance structure of the relief organisation. Even though by its act and regulations, the relief organisation is supposed to be autonomous but in practice, it is controlled by the central government through its leadership appointments as well as the funding. Accordingly, decision-making process is often top-down approach instead of vice-versa and therefore, to succeed, the decision-making process must move from bottom to top. 
Socio-cultural factors such as the mind-set of workers based on their cultural orientation attitude to government projects was mentioned. It was revealed that successful operations need fieldworkers who have a positive mind-set about government work and also good attitudes towards victims by perceiving their duties as work rather than voluntary work. Also, victims and their local areas positive belief system is a critical success factor. Another critical success factors are within the area of education and training. This relates to education of the general populace about disaster management and also, training of fieldworkers. Thus, having an informed knowledge about causes and effects of disaster, and how to manage them when they occur will conscientised the general public - hence, making the relief workers work easy. This also related to the cultural orientation - thus, if the local people are educated about their cultural orientation towards disaster, they will allow and/or provide maximum support to relief workers, hence, being critical to their operational success. On the other hand, members of the fieldworkers need to have constant training about the various aspect of post-disaster management in order to have the possibility of being successful.

In infrastructure, sufficient availability of healthcare facilities, road network, communication network, and warehouses and depots are critical for successful post-disaster operations. Lastly, stakeholder involvement and co-operations are panacea to successful disaster operations. It was revealed that relief organisations do not operate in isolation and therefore full co-operation among other stakeholders such as local community, the security agencies and donor agencies are critical to humanitarian operation in postdisaster management.

\subsection{Limitations and Suggestions for Future Research}

Using semi-structured interview implies that findings may not be generalised as the sample may not reflect the entire country. However, this is an exploratory study that sets the foundation for future studies that may involve larger sample sizes. Also, a questionnaire survey could be developed to compare the various success factors in order to identify the most important critical success factors. Further, future studies could look at the relationships between the various sets of related factors identified as factors that are critical to 
humanitarian supply chain management and their level of impact on humanitarian operations. Moreover, by default, some of the factors are internal to the relief organisations; others are external to the relief organisations. However, this study did not focus on making a clear distinction and as such future studies could look at this distinction and the relationship between these two broad categorisations. In addition, given that extensive literature in the field of humanitarians operations and other commercial operations have identified technology as an important factor in relief operations and yet, the study's participants did not consider and/or mentioned this as an important critical success factor, there is the need for future studies to look into this area into details in order to prescribe how technology could be incorporated into disaster management in Africa and sub-Saharan Africa in particular.

\section{Conflict of Interest}

There is no conflict of interest.

\section{Reference}

Aboagye, D., Dari, T., and Koomson, J. 2013. '’Risk Perception and Disaster Management in the Savannah Region of Ghana’, International Journal of Humanities and Social Science 3(3), 85-96.

Anaya-Arenas, A. M., Ruiz, A, and Renaud, J. 2018. '’Importance of fairness in humanitarian relief distribution’, Production Planning \& Control, 29(14), 1145-1157. Albala-Bertrand, J. 1993.

‘’Natural Disaster Situations and Growth: A Macroeconomic Model for Sudden Disaster Impacts’, World Development, 21, 1417-34.

Alca'ntara-Ayala, I. 2002. 'Geomorphology, natural hazards, vulnerability and prevention of natural disasters in developing countries”, Geomorphology 47(1-4), 107-124.

Altay, N. and Green, W. G. 2006. ‘'OR/MS research in disaster operations management’, European Journal of Operations Research, 175 (1), 475-493. 
Altay, N., Gunasekaran, A., Dubey, R. and Childe, S. J. 2018. 'Agility and resilience as antecedents of supply chain performance under moderating effects of organizational culture within the humanitarian setting: a dynamic capability view’', Production Planning \& Control, 29:14, 1158-1174, DOI: 10.1080/09537287.2018.1542174.

Altay, N. and Pal, R. 2014. ''Information Diffusion among Agents: Implications for Humanitarian Operations”, Production and Operations Management, 23(6), 1015-1027.

Asumadu-Sarkodie, S., Owusu, P., A., and Rufangura, P. 2015. ''Impact analysis of flood in Accra, Ghana’, Advances in Applied Science Research, 6(9), 53-78.

Balcik, B., Beamon, B. M., Krejci, C. C., Muramatsu, K. M., and Ramirez, M. 2010. '’Coordination in humanitarian relief chains: Practices, challenges and opportunities’', International Journal of Production Economics, 126, 22-34.

Bempah, S. A., and Øyhus, A. O. 2017. 'The role of social perception in disaster risk reduction: Beliefs, perception, and attitudes regarding flood disasters in communities along the Volta River, Ghana”, International Journal of Disaster Risk Reduction, 23, 104-108.

Black, I. 2006. '’The presentation of interpretivist research', Qualitative Market Research: An International Journal, 9(4), 319-324.

Braun, V. and Clarke, V. 2012. 'What is Thematic Analysis? - How to Use Thematic Analysis', [online] Sites.google.com. Available at:

https://sites.google.com/site/howtousethematicanalysis/home/what-is-thematic-analysis, (Accessed 6 February 2018).

Bryman, A. and Bell, E. 2015. '’Business research methods’, 4th ed. Oxford: Oxford Univ. Press.

Carson, D., Gilmore, A., Perry, C. and Gronhaug, K.2001. ''Qualitative Marketing Research', Sage Publications, London. 
CHINA, U. 2001. '’Natural Disaster Management', Available at: WWW/theme/HTML/disaster.shtml, (Accessed 12 July 2018).

Chopra, S. and Meindl, P. 2007. 'Supply chain management. Strategy, planning \& operation’, in: Das Summa Summarum des Management: Springer, 265-275.

Cigolini, R. and Rossi, T. 2006. '’A note on supply risk and inventory outsourcing”, Production Planning and Control, 17(4), 424-437.

Collis, J. and Hussey, R. 2014. Business research. Basingstoke: Palgrave Macmillan.

Cooper, M. C., Lambert, D. M. and Pagh, J. D. 1997. '’Supply chain management: more than a new name for logistics”, International Journal of Logistics Management 8 (1), 1-14.

Crumbly, J. and Carter, L. 2015. 'The impact of information technology on product recalls: exploring the role of the six “Ts” of supply chain management”, Production Planning \& Control, 26(12), 958968. http://dx.doi.org/10.1080/09537287.2015.1009521

Denzin N. K. and Lincoln, Y. S. 2005), Handbook of qualitative research Thousand Oaks, CA: Sage.

Fritz Institute, 2017. '’From logistics to supply chain management: the PATHE forward in the humanitarian sector”, Available at: www.fritzinstitute.org/PDFs/WhitePaper/FromLogisticsto.pdf. (Accessed 24 June 2019).

Gibson, B. J. Mentzer, J. T. and Cook, R. L. 2005. 'Supply chain management: the pursuit of a consensus definition’, Journal of Business Logistics 26 (2), 17-25.

Gonçalves, P. and Castañeda, J. A. 2018. 'Stockpiling supplies for disaster response: an experimental analysis of prepositioning biases’, Production Planning \& Control, 29:14, 1207-1219, DOI: 10.1080/09537287.2018.1542173

Gualandris, J. and Kalchschmidt, M. 2015. '’Mitigating the effect of risk conditions on supply disruptions: the role of manufacturing postponement enablers’', Production Planning \& Control, 26(8), 637-653. 
Heaslip, G. 2018. ''Editorial for special issue on: humanitarian operations management', Production Planning \& Control, 29(14), 1127-1129, DOI:10.1080/09537287.2018.1542158.

Hillman, A. J., Withers, M. C., and Collins, B. J., 2009. Resource dependence theory: A review. Journal of Management, 35, 1404-1427.

Hudson, L., and Ozanne, J. (1988). Alternative Ways of Seeking Knowledge in Consumer Research. Journal of Consumer Research, 14(4), 508-521.

Jahre, M., Persson, G. Kovács, G. and Spens, K. M. 2007. 'Humanitarian logistics in disaster relief operations’, International Journal of Physical Distribution \& Logistics Management 37 (2), 99-114.

John, L., Gurumurthy, A., Soni, G. and Jain, V. 2018. '’Modelling the inter-relationship between factors affecting coordination in a humanitarian supply chain: a case of Chennai flood relief', Annals of Operations Research, 1-32. https://doi.org/10.1007/s10479-018-2963-3.

Kabra, G. and Ramesh, A. 2016. '’Information Technology, Mutual Trust, Flexibility, Agility, Adaptability: Understanding Their Linkages and Impact on Humanitarian Supply Chain Management Performance’, $\quad$ Risk, Hazards \& Crisis in Public Policy, 7(2), 79-103. https://doi.org/10.1002/rhc3.12096.

Kalambay, K. and Abdulmumini, U. 2018. 'Disaster preparedness and response in the African Region: Current situation and way forward. World Health Organization, Regional Office for Africa.’' Disaster Control No.15.

Klomp, J. and Valckx, K. 2014. ''Natural disasters and economic growth: A meta-analysis.' Global Environmental Change 26, 183-195.

Lin, Y., Batta, R., Rogerson, P. A., Blatt, A., and Flanigan, M. 2011. '’A logistics model for emergency supply of critical items in the aftermath of a disaster.'’ Socio-Economic Planning Sciences 45, 132145. 
Liu, D., Li, Y., Shen, X., Xie, Y., \& Zhang, Y. 2018. Flood risk perception of rural households in western mountainous regions of Henan Province, China. International Journal of Disaster Risk Reduction, 27, $155-160$.

Loayza, N. V., Olaberria, E., Rigolini, J., and Christiaensen, L. 2012. '’Natural Disasters and Growth: Going Beyond the Averages.’' World Development 40(7), 1317-1336.

Ludema, M. and Roos, H. 2000. 'Military and civil logistic support of humanitarian relief Operations", INCOSE International Symposium 10 (1), 135-142.

Martinez, A. J. P., Stapleton, O. and Wassenhove, L. N. V. 2011. ''Field vehicle fleet management in humanitarian operations: A case-based approach’’. Journal of Operations Management 29, 404-421.

Miles, M. and Huberman, M. 1994. 'The Handbook of Social Work Research Method', London: Sage Publication.

Olu, O., Usman, A., Manga, L., Anyangwe, S., Kalambay, K., Nsenga, N., Woldetsadik, S., Hampton, C., Nguessan, F. and Benson, A. 2016. ' 'Strengthening health disaster risk management in Africa: multisectoral and people-centred approaches are required in the post-Hyogo Framework of Action era.'” BMC Public Health, 16(691), 1-8.

Oloruntoba, R. and Gray, R. 2006. 'Humanitarian aid: an agile supply chain? Supply Chain Management: International Journal 11(2), 115-120.

Reid, P., and Niekerk, D. V. 2008. '’A model for a multi-agency response management system (MARMS) for South Africa.’' Disaster Prevention and Management: An International Journal, 17(2), 244-255.

Safran, P. 2003. 'A strategic approach for disaster and emergency assistance.' in Contribution to in: Proceedings of the 5th Asian Disaster Reduction Center International Meeting and the 2nd UN-ISDR Asian Meeting, 15-17.

Sahebi, I. G., Arab, A. and Moghadam, M. R. S. 2017. 'AAnalyzing the barriers to humanitarian supply chain management: A case study of the Tehran Red Crescent Societies’, International Journal of Disaster Risk Reduction 24, 232-241. 
Saunders, M., Lewis, P. and Thornhill, A. 2015. ''Research methods for business students', 6th ed. Harlow [etc.]: Pearson Education Limited.

Schumacher, I. and Strobl, E. 2011. ''Economic development and losses due to natural disasters: The role of hazard exposure.’' Ecological Economics 72, 97-105.

Shareef, M. A., Dwivedi, Y. K., Mahmud, R., Wright, A., Rahman, M. M., Kizgin, H. \& Rana, N. P. 2018. ''Disaster management in Bangladesh: developing an effective emergency supply chain network’, Annals of Operations Research, https://doi.org/10.1007/s10479-018-3081-y.

Strobl, E. 2012. ' The economic growth impact of natural disasters in developing countries: Evidence from hurricane strikes in the Central American and Caribbean regions", Journal of Development Economics, 97(1), 130-141.

The AU/NEPAD, 2004. ' Disaster Risk Reduction for Sustainable Development in Africa. Africa Regional Strategy for Disaster Risk Reduction.” Available at: https://www.unisdr.org/files/4038_africaregionalstrategy1.pdf. (Accessed 8 October 2018).

Thomas, A. S. and Kopczak, L. R. 2005. 'From logistics to supply chain management: the path forward in the humanitarian sector.'’ Fritz Institute 15, 1-15.

Tol, R., and Leek. F., 1999. Economic Analysis of Natural Disasters, in Climate, Change and Risk, edited by T. E. Downing, A. J. Olsthoorn, and R. S. T. Tol. London: Routledge, 308-27.

Pettit, S. J. and Beresford, A. K. 2005. '’Emergency relief logistics: an evaluation of military, nonmilitary and composite response models’, International Journal of Logistics Research and Applications 8 (4), 313-331.

Pettit, S. and Beresford, A. 2009. "Critical success factors in the context of humanitarian aidsupply chains", International Journal of Physical Distribution \& Logistics Management, 39(6), 450-468.

Pfeffer, J. and Salancik, G. R. 1978. 'The External Control of Organizations: A Resource Dependence Perspective’’, New York, NY, Harper and Row. 
United Nations, 1992. 'Glossary: Internationally Agreed Glossary of Basic Terms Related to Disaster Management’, UN International Decade for Natural Disaster Reduction, Geneva’.

United Nations Development Programme, 2004. '’Reducing Disaster Risk: A Challenge for Development.'

New York: Bureau for Crisis Prevention and Recovery, United Nations.

Van Wassenhove, L. N. 2006. ''Humanitarian aid logistics: supply chain management in high gear.' Journal Operations Research Society 57 (5), 475-489.

Wang, X., Tiwari, P. and Chen, X. 2017. 'Communicating supply chain risks and mitigation strategies: a comprehensive framework’, Production Planning \& Control 28(13), 1023-1036.

Wagner, S. M. and Thakur-Weigold, B. 2018. '’Supporting collaboration in humanitarian supply chains insights from a design science project”, Production Planning \& Control, 29:14, 1130-1144, DOI: 10.1080/09537287.2018.1542175.

Zhou, Q., Huang,W., and Zhang, Y. 2011. '’Identifying critical success factors in emergency management using a fuzzy DEMATEL method’', Safety Science 49, 243-252

\section{Appendix}

Table 3. In-depth Semi-structured Interview Profile

\begin{tabular}{|l|l|l|l|l|l|l|}
\hline Respondents & $\begin{array}{l}\text { Posit } \\
\text { ion }\end{array}$ & Age & Education & $\begin{array}{l}\text { Years of } \\
\text { Experience in } \\
\text { Current position }\end{array}$ & $\begin{array}{l}\text { Work Experience } \\
\text { in Disaster } \\
\text { Operations } \\
\text { Management }\end{array}$ & $\begin{array}{l}\text { Overall } \\
\text { Work } \\
\text { Experience }\end{array}$ \\
\hline $\begin{array}{l}\text { R1(NADMO Official - } \\
\text { Senior Disaster } \\
\text { support) }\end{array}$ & & 55 & Masters & 10 & 13 & 30 \\
\hline R2 (NADMO Official) & & 52 & $\begin{array}{l}\text { Masters/Prof } \\
\text { essional }\end{array}$ & 12 & 13 & 27 \\
\hline R3 (NADMO Official) & & 40 & $\begin{array}{l}\text { BA/ } \\
\text { Professional }\end{array}$ & 10 & 12 & 20 \\
\hline R4 (NADMO Official) & & 46 & $\begin{array}{l}\text { BA/ } \\
\text { Professional }\end{array}$ & 2 & 18 & 5 \\
\hline $\begin{array}{l}\text { R5 (NADMO } \\
\text { OFFICIAL - field } \\
\text { officer) }\end{array}$ & 27 & $\begin{array}{l}\text { HND } \\
\text { Diploma }\end{array}$ & 5 & 5 & 9 \\
\hline $\begin{array}{l}\text { R6 (NADMO Field } \\
\text { Officer) }\end{array}$ & & 33 & \begin{tabular}{l} 
SSCE \\
\hline
\end{tabular} & 7 & 7 & \\
\hline
\end{tabular}




\begin{tabular}{|l|l|l|l|l|l|l|}
\hline $\begin{array}{l}\text { R7 (Operations } \\
\text { Manager) }\end{array}$ & 58 & Masters & 10 & 10 & 27 \\
\hline $\begin{array}{l}\text { R8 (NADMO Disaster } \\
\text { Control officer) }\end{array}$ & 49 & $\begin{array}{l}\text { Masters/Prof } \\
\text { essional }\end{array}$ & 13 & 13 & 24 \\
\hline R9 (NADMO Officer) & & 40 & Masters & 8 & 10 & 12 \\
\hline R10 (NADMO Official) & & 46 & BA (Hons) & 15 & 15 & 21 \\
\hline R11 (Administrator) & & 37 & BA/PgD & 6 & 10 & 11 \\
\hline R12 (Field Officer) & & 34 & BA & 8 & 8 & 14 \\
\hline R13 (Co-ordinator) & & 41 & Masters & 16 & 16 & 31 \\
\hline R14 (Administrator) & & 54 & Masters & 5 & 27 & 20 \\
\hline $\begin{array}{l}\text { R15(Administrative } \\
\text { Director) }\end{array}$ & 46 & BA (Hons) & 8 & 16 & 3 \\
\hline R16 (Field Officer) & & 21 & SSCE & 3 & 3 & 4 \\
\hline $\begin{array}{l}\text { R17(Field Officer) } \\
\text { R18 (Operation }\end{array}$ & 26 & $\begin{array}{l}\text { SSCE/Profe } \\
\text { ssional }\end{array}$ & 2 & 2 & 22 \\
\hline $\begin{array}{l}\text { coordinator) } \\
\text { P19 (Field Officer) }\end{array}$ & 47 & $\begin{array}{l}\text { BA/PgD/Prof } \\
\text { essional }\end{array}$ & 6 & 11 & 19 \\
\hline R20 (Field Officer) & & 27 & SSCE & 5 & 15 & 4 \\
\hline
\end{tabular}


